\title{
BMJ Open Knowledge and practice of health workers about control and prevention of multidrug-resistant tuberculosis in referral hospitals, Ethiopia: a cross- sectional study
}

Kefyalew Addis Alene, ${ }^{\circ 1}$ Akilew Awoke Adane, ${ }^{1}$ Sisay Yifiru, ${ }^{2}$ Bikes Destaw Bitew, ${ }^{1}$ Aynishet Adane, ${ }^{2}$ Digsu Negese Koye ${ }^{1}$

To cite: Alene KA, Adane AA, Yifiru S, et al. Knowledge and practice of health workers about control and prevention of multidrug-resistant tuberculosis in referral hospitals, Ethiopia: a cross-sectional study. BMJ Open 2019;9:e022948. doi:10.1136/ bmjopen-2018-022948

- Prepublication history and additional material for this paper are available online. To view these files, please visit the journal online (http://dx.doi. org/10.1136/bmjopen-2018022948).

Received 16 March 2018 Revised 7 August 2018 Accepted 19 December 2018

A) Check for updates

(C) Author(s) (or their employer(s)) 2019. Re-use permitted under CC BY-NC. No commercial re-use. See rights and permissions. Published by BMJ.

${ }^{1}$ Institute of Public Health, College of Medicine and Health Sciences, University of Gondar, Gondar, Ethiopia

${ }^{2}$ School of Medicine, College of Medicine and Health Sciences, University of Gondar, Gondar, Ethiopia

Correspondence to Dr Kefyalew Addis Alene; kefyalew.alene@anu.edu.au

\section{ABSTRACT}

Objective The aim of this study was to assess the knowledge and practice of health workers about multidrug-resistant tuberculosis (MDR-TB) prevention and control.

Study design and settings A cross-sectional study was conducted at Gondar University Referral Hospital and Felege Hiwot Referral Hospital.

Participants Randomly selected health workers (ie, medical doctor, nurse, health officer, pharmacy, medical laboratory and midwifery) were the study participants.

Outcome measures The main outcomes were knowledge and self-reported practice of health workers about MDRTB.

Results A total of 377 health workers (with a response rate of $93.7 \%$ ) participated in the study. The majority of respondents were nurses $(52.5 \%, \mathrm{n}=198)$ and medical doctors $(15.6 \%, n=59)$. The mean knowledge score was seven out of $10 ; 149(39.5 \%)$ of respondents scored seven or more which was considered as good knowledge. MDR-TB knowledge of health workers was significantly associated with having a postgraduate degree (adjusted odds ratio $(\mathrm{AOR})=5.78 ; 95 \% \mathrm{Cl} 2.33$ to 14.33), taking infection prevention training ( $\mathrm{AOR}=1.79$; $95 \% \mathrm{Cl} 1.00$, to 3.17 ) and having a history of tuberculosis (TB) (AOR=1.85; $95 \% \mathrm{Cl} 1.12$, to 3.03 ). The mean self-reported practice score was four out of seven; one-fifth $(19.6 \%)$ of respondents scored four or more which was considered as good practice. Self-reported practice of health workers was significantly associated with working at internal medicine $(A O R=4.64 ; 95 \% \mathrm{Cl}$ 1.99, to 10.81) and paediatrics ( $A O R=3.85 ; 95 \% \mathrm{Cl} 1.11$, to 13.34) wards, being in the age groups of $26-30$ years $(\mathrm{AOR}=2.70 ; 95 \% \mathrm{Cl} 1.27$, to 5.76 ), and 30 years and above ( $\mathrm{AOR}=4.42 ; 95 \% \mathrm{Cl} 1.77$, to 11.00 ).

Conclusions This study found low knowledge and self-reported practice score among health workers. MDR-TB knowledge of health workers was significantly associated with educational status, infection prevention training and previous history of TB. This finding highlights the potential of providing MDR-TB training for health workers to increase their knowledge about MDR-TB.

\section{Strengths and limitations of this study}

- This study is the first to explore the knowledge and practice of health workers regarding multidrug-resistant tuberculosis in two large referral hospitals in Ethiopia.

- The participants were selected randomly among different health workers such as medical doctor, nurses, health officer, pharmacy, medical laboratory and midwifery.

- There is a possibility that health workers may not report their actual practices as the information was self-reported.

- The findings from this study may not be generalisable to health workers in other hospitals in the country.

\section{INTRODUCTION}

Multidrug-resistant tuberculosis (MDR-TB) is defined as tuberculosis (TB) that is resistant to at least isoniazid and rifampin, the two most effective first-line TB drugs. ${ }^{1}$ The emergence of MDR-TB is a major public health problem and is an obstacle for national and global TB control programmes. ${ }^{2}$ Globally, nearly half a million people are estimated to have MDR-TB annually, and only one-fourth of them get adequate treatment. ${ }^{3-5}$ In 2016, there were an estimated 490000 new cases of MDR-TB and approximately 240000 deaths from MDR-TB ${ }^{67}$ Treatment for MDR-TB has substantially longer duration, higher costs and more toxicity than the treatment for drug-susceptible TB. ${ }^{8}$

MDR-TB occurs in patients either due to the development of drug resistance during a course of first-line TB treatment (ie, acquired MDR-TB) ${ }^{9}$ or due to the transmission of a drug-resistant strain from an infectious patient to a susceptible host (ie, 
primary MDR-TB).$^{10}$ Acquired MDR-TB occurs as a result of sub-optimal first-line TB treatment related to healthcare providers or patient factors. ${ }^{11}{ }^{12}$ There is increasing evidence that primary MDR-TB is common and that many patients with MDR-TB had it from the start of treatment. ${ }^{13-15}$ Inadequate knowledge and poor practice of health professional towards the prevention and control of MDR-TB may exacerbate the transmission of MDR-TB in healthcare settings. ${ }^{9}$ Health workers have the potential to contact with MDR-TB patients and are very important stakeholders in healthcare settings to combat MDR-TB. Previous studies have been conducted to assess the knowledge and practices of health workers towards the prevention and control of TB. ${ }^{16-20}$ However, there is a limited study regarding the knowledge and practices of health workers about the prevention and control of MDR-TB in Ethiopia.

Ethiopia is one of 30 high TB and MDR-TB burden countries. ${ }^{21}$ The incidence of TB has decreased over time in Ethiopia following the implementation of different interventions, including the delivery of $\mathrm{TB}$ care by health extension workers and the expansion of directly observed therapies. ${ }^{22}{ }^{23}$ However, the number of MDR-TB cases has increased over time and has become a challenge for the national TB control and prevention programme. ${ }^{23} 24$ Assessing the knowledge and practice of health workers on MDR-TB, and identifying factors associated with inadequate knowledge and low practice are important for the prevention and control of MDR-TB. Therefore, the aim of this study was to assess the knowledge and self-reported practice of health works related to MDR-TB and to identify factors associated with inadequate knowledge and low self-reported practice of health workers toward the prevention and control of MDR-TB in Amhara region referral hospitals, Ethiopia.

\section{METHODS}

\section{Study design and setting}

This was a cross-sectional study conducted from March to May 2014 among health workers in Amhara regional referral hospitals. Amhara region is the second largest region in Ethiopia. The region has five referral hospitals, and the study was conducted in two (randomly selected) of these five referral hospitals: Gondar University Referral Hospital and Felege Hiwot Referral Hospital. During the study period, Amhara region referral hospitals have 304 medical doctors, 3790 nurses, 434 public health officer and 287 midwiferies. TB is the leading cause of death among an infectious disease in the region. ${ }^{25} \mathrm{~TB}$ detection rate (all forms), which is defined as the number of new and relapse TB cases notified in a given year, divided by the estimated number of incident TB cases for the same year, was $34 \%$ in Amhara region. ${ }^{25}$

Gondar University Hospital is the oldest hospital in the country which is located in Gondar, $750 \mathrm{~km}$ northwest of Addis Ababa (the capital city of Ethiopia). It provides healthcare services for a catchment population of approximately 5 million people in North Gondar and the adjacent zones. The hospital established the MDR-TB treatment centre in 2010 and it had around 80 MDR-TB patients during the data collection period.

Felege Hiwot Referral Hospital is located in Bahir Dar (the capital city of Amhara National Regional State), $562 \mathrm{~km}$ northwest of Addis Ababa and $180 \mathrm{~km}$ southeast of Gondar. The hospital serves a catchment population of more than 5 million and about 500 clients visit the hospital daily. The hospital has 273 beds and offers different specialised services in four major departments: Pediatric, Surgery, Gynecology and Obstetrics and Internal Medicine.

\section{Sample size and sampling procedures}

The sample size for this study was determined using single population proportion formula, by taking the following assumptions: margin of error $(5 \%)$, expected response rate $(5 \%)$ and CI $(95 \%)$. There was no study in Ethiopia that showed the prevalence of good knowledge or practice of health workers about MDR-TB. Therefore, to allow for maximum variation, we took a prevalence of $50 \%$. Based on these assumptions, the final sample size was 402 . To select the study participant random sampling technique was used. First, two of the five referral hospitals in Amhara region were selected randomly (ie, Gondar University Referral Hospital and Felege Hiwot Referral Hospital). Then the sample size was proportionally allocated to these hospitals based on their number of health workers. The list of health workers (ie, sampling frame) was obtained from the office of human resource of each hospital. Finally, the sample was selected from each hospital by simple random sampling technique. The sample includes a medical doctor, nurse, health officer, pharmacy, medical laboratory and midwifery. Those health workers who were temporarily employed in the hospitals were excluded from the study.

\section{Data collection instrument}

The questionnaire for this study was developed by the research team based on the Ethiopia Programmatic Management of Drug-resistant Tuberculosis Guideline $2013{ }^{26}$ the 2014 WHO Guidelines for the Programmatic Management of Drug-resistant Tuberculosis ${ }^{27}$ and previous studies. ${ }^{28-32}$ The details of the questionnaire are available as an additional file in the online supplementary appendix. The questionnaire contains the following section: socio-demographic profile of the participants (such as age, sex, marital status, level of education, years of experience, type of occupation) and questions about knowledge and practice of health workers about MDR-TB. Knowledge of health workers was assessed based on the number of correct answers provided to 10 closed-ended questions (ie, multiple choice, yes/no and true/false) on the definition, cause, diagnosis, treatment and prevention of MDR-TB. Each attracts a score of 1 (for a correct answer) or 0 (for a wrong answer). The knowledge score was calculated for each study participants by summing up 
the points of all questions and the score ranging from 0 to 10 . Then knowledge score was categorised into good and poor score if it is equal to or above the mean and below the mean, respectively. Similarly, the self-reported practice of health workers about MDR-TB prevention and control was assessed by seven questions. The practice questions were about access to the MDR-TB guideline, implementation of cross ventilation in the hospital, provision of health education to the patients about MDR-TB, and access and use of Masks N95. If there was a self-reported practice earned a score of 1 otherwise 0 . Participants who scored equal to or above the mean were considered as having a good practice and below the mean considered as a poor practice.

To improve the adequacy, accuracy and appropriateness of the questionnaire content and face validation was performed. Prior to the main survey, the questioner was pre-tested among 20 health workers (ie, $5 \%$ of the sample) in other hospitals. The questionnaire was administered to study participants with the help of data collectors. The questionnaires were then collected after 1 or 2 days. The questionnaire front page contains information, describing the survey and asking for their voluntary participation. By reading and responding, they gave their consent.

\section{Data analysis}

The data were entered and analysed using the SPSS V.20.0. The data were cleaned and checked for accuracy. Percentages and numbers were used to summarise categorical data. Mean and SD were used to describe normally distributed continuous variables. A bivariate logistic regression model was first fitted and the variables which had a $\mathrm{p}$ value $<0.2$ in the bivariate analysis were fitted in the final multivariable logistic regression model. Variables with a $\mathrm{p}$ value $<0.05$ in the final multivariable logistic regression model were considered significantly associated with the dependent variables (ie, knowledge and practice). Crude and adjusted ORs with $95 \%$ CI were calculated to measure the strength of association between the dependent and independent variables.

\section{Patient and public involvement}

No patients or public were involved in this research.

\section{RESULTS}

\section{Socio-demographic characteristics}

A total of 377 health workers participated in the study, with a response rate of $93.7 \%$. Table 1 shows the demographic profile of the respondents. The majority of respondents were nurses $(52.5 \%, \mathrm{n}=198)$ and medical doctors $(15.6 \%$, $\mathrm{n}=59)$. The mean age of the participants was $27.6( \pm 4.7 \mathrm{SD})$ years. Most of the respondents were males $(60.7 \%, \mathrm{n}=229)$ and BSc degree holders (62.6\%, $\mathrm{n}=236)$.

One-third $(36.6 \%, \mathrm{n}=138)$ of the respondents were previously diagnosed for $\mathrm{TB}$, and $140(37.1 \%)$ were working at outpatient departments (OPD). The majority $(80 \%, \mathrm{n}=298)$
Table 1 Socio-demographic characteristics of health workers at Gondar University Referral Hospital and Felege Hiwot Referral Hospital, Northwest Ethiopia

\begin{tabular}{|c|c|c|}
\hline Variables & Number & Per cent \\
\hline \multicolumn{3}{|l|}{ Working site } \\
\hline Internal medicine & 79 & 21 \\
\hline Surgery & 46 & 12.2 \\
\hline Gynaecology and obstetrics & 43 & 11.4 \\
\hline Paediatrics & 52 & 13.8 \\
\hline OPD and others & 157 & 41.6 \\
\hline \multicolumn{3}{|l|}{ Age (year) } \\
\hline$<25$ & 130 & 34.5 \\
\hline $26-30$ & 189 & 50.1 \\
\hline$>30$ & 58 & 15.4 \\
\hline \multicolumn{3}{|l|}{ Sex } \\
\hline Male & 229 & 60.7 \\
\hline Female & 148 & 39.3 \\
\hline \multicolumn{3}{|l|}{ Marital status } \\
\hline Married & 155 & 41.9 \\
\hline Not married & 222 & 49.1 \\
\hline \multicolumn{3}{|l|}{ Profession } \\
\hline Doctor of Medicine & 59 & 15.6 \\
\hline Nurse & 198 & 52.5 \\
\hline Medical laboratory & 44 & 11.7 \\
\hline Other health professionals & 76 & 20.1 \\
\hline \multicolumn{3}{|l|}{ Educational level } \\
\hline Diploma & 75 & 19.9 \\
\hline BSc degree & 236 & 62.6 \\
\hline Postgraduate and above & 66 & 17.5 \\
\hline \multicolumn{3}{|l|}{ Staff categories } \\
\hline Teaching staff & 56 & 14.9 \\
\hline Hospital staff & 321 & 85.1 \\
\hline \multicolumn{3}{|l|}{ Working experience (years) } \\
\hline$<3$ & 139 & 36.9 \\
\hline 03June & 90 & 23.9 \\
\hline$>6$ & 148 & 39.3 \\
\hline \multicolumn{3}{|l|}{ Ever diagnosed for TB } \\
\hline Yes & 138 & 36.6 \\
\hline No & 239 & 63.4 \\
\hline \multicolumn{3}{|l|}{ Trained for infection prevention } \\
\hline Yes & 79 & 21 \\
\hline No & 298 & 79 \\
\hline
\end{tabular}

OPD, outpatient departments; TB, tuberculosis.

of study participants were not trained for infection prevention within the last 12 months. One hundred and forty-eight $(39.3 \%)$ of respondents had work experience of more than 6years. 

Table 2 Number and per cent of correct response among
health profession towards all knowledge questions

\begin{tabular}{|c|c|c|}
\hline $\begin{array}{l}\text { The correct response to } \\
\text { knowledge questions }\end{array}$ & Number & Per cent \\
\hline $\begin{array}{l}\text { MDR-TB is defined as TB that } \\
\text { is resistant to isoniazid and } \\
\text { rifampicin }\end{array}$ & 264 & 70.0 \\
\hline $\begin{array}{l}\text { MDR-TB is transmitted by } \\
\text { droplet spread }\end{array}$ & 345 & 91.5 \\
\hline $\begin{array}{l}\text { MDR-TB occur when TB } \\
\text { treatments are not properly } \\
\text { administered }\end{array}$ & 357 & 94.7 \\
\hline $\begin{array}{l}\text { All people with MDR-TB } \\
\text { infection may not have } \\
\text { symptoms }\end{array}$ & 148 & 39.3 \\
\hline $\begin{array}{l}\text { A cough or chest pain is the } \\
\text { most common symptom of } \\
\text { pulmonary MDR-TB }\end{array}$ & 221 & 58.6 \\
\hline $\begin{array}{l}\text { Culture with drug susceptibility } \\
\text { test is the best diagnostic } \\
\text { methods for MDR-TB }\end{array}$ & 368 & 97.6 \\
\hline $\begin{array}{l}\text { Culture conversion is the major } \\
\text { element to assess MDR-TB } \\
\text { treatment cure }\end{array}$ & 241 & 63.9 \\
\hline $\begin{array}{l}\text { MDR-TB treatment takes } \\
18 \text { months and above }\end{array}$ & 209 & 55.4 \\
\hline $\begin{array}{l}\text { Nationally recommended MDR- } \\
\text { TB treatment regimen }\end{array}$ & 168 & 44.6 \\
\hline $\begin{array}{l}\text { Putting on N95 can reduce the } \\
\text { risk of MDR-TB transmission }\end{array}$ & 314 & 83.3 \\
\hline
\end{tabular}

MDR-TB, multidrug-resistant tuberculosis; TB, tuberculosis.

\section{Knowledge of health workers about MDR-TB}

The mean knowledge score was seven points out of a total possible score of 10 points. Two-fifth $(39.5 \%)$ (95\% CI $35.0 \%$ to $44.3 \%)$ of respondents scored equal to or more than the mean score which was categorised as good knowledge. Table 2 shows the number and percentage of correct responses of health workers for knowledge questions. The majority of respondents knew that MDR-TB occurs when TB treatments are not properly administered (97.6\%), culture with drug susceptibility testing (DST) is the best diagnostic methods for MDR-TB (94.7\%), and MDR-TB is transmitted by droplet spread $(91.5 \%)$. Knowledge was less accurate regarding the treatment and symptoms of MDR-TB. Less than half of the respondents answered questions correctly about the nationally recommended treatment regimen $(44.6 \%)$ and the most common symptoms $(39.3 \%)$ of MDR-TB. Knowledge gap was also observed among respondents regarding the duration of MDR-TB treatment $(55.4 \%)$ (table 2 ).

In the bivariate analysis, sex, working sit, profession, educational status, staff categories, previous history of $\mathrm{TB}$, and taking infection prevention training were significantly associated with knowledge of respondents about MDR-TB. However, in the stepwise multivariate analysis, educational level, previous history of TB, and taking infection prevention training were remained significantly associated with knowledge of respondents about MDR-TB after controlling other factors (table 3).

Accordingly, health workers who had a postgraduate degree were more likely to have good knowledge about MDR-TB than health workers who had a diploma (adjusted odds ratio $(\mathrm{AOR})=5.78 ; 95 \%$ CI 2.33 to 14.33 ). Those health workers who had been trained for infection prevention were more likely to have good knowledge about MDR-TB than those health workers who had not been trained for infection prevention (AOR=1.79; 95\% CI 1.00 to 3.17$)$. Similarly, health workers who had a history of TB were more likely to have good knowledge about MDR-TB than health workers who had no a history of $\mathrm{TB}(\mathrm{AOR}=1.85 ; 95 \%$ CI 1.12 to 3.03$)$.

\section{Practices of health workers towards the prevention and control of MDR-TB}

A total of $123(32.6 \%)$ respondents reported having access to the MDR-TB guideline, and $110(29.17 \%)$ mentioned that they referred to the guidelines when providing care to TB or MDR-TB suspected patients. One hundred and sixty-three $(43.2 \%)$ respondents reported the implementation of cross-ventilation in their working room. More than a quarter $103(27.3 \%, \mathrm{n}=103)$ of participants reported that they always wore a protective mask (N95) when carrying out clinical procedures and attending patients. The mean self-reported practice score was four points out of a total possible score of seven points. Less than a quarter $(19.6 \%$; 95\% CI $16.2 \%$ to $23.8 \%)$ of health workers were scored equal to or above the mean score which was categorised as good practice towards the prevention and control of MDR-TB.

To identify factors associated with the self-reported practice of MDR-TB, logistic regression models were fitted. In the bivariate analysis, working site, the age of respondents, sex, profession, educational level, and knowledge about MDR-TB were significantly associated with the self-reported practice. However, in the multivariate analysis, working site, the age of respondents, and profession were significantly associated with self-reported practice (table 4). Health workers who were working at internal medicine $(\mathrm{AOR}=4.64$; 95\% CI 1.99 to 10.81$)$ and Paediatric (AOR=3.85; 95\% CI 1.11 to 13.34 ) wards were more likely to have good self-reported practice than health workers who were working at OPD. Those health workers in the age group of 26-30 years $(\mathrm{AOR}=2.70 ; 95 \%$ CI 1.27 to 5.76$)$ and $>30$ years $(\mathrm{AOR}=4.42$; $95 \%$ CI 1.77 to 11.08 ) were more likely to have good self-reported practice as compared with those health workers with the age group of $<25$ years. Nurses were more likely to have good self-reported practice than medical doctors $(\mathrm{AOR}=4.49 ; 95 \%$ CI 1.03 to 19.47$)$.

\section{DISCUSSION}

Health workers have a key role in the prevention and control of MDR-TB, especially in resource-limited settings 
Table 3 Factors associated with knowledge of health workers about MDR-TB at Gondar University Referral Hospital and Felege Hiwot Referral Hospitals, Northwest Ethiopia

\begin{tabular}{|c|c|c|c|c|}
\hline \multirow[b]{2}{*}{ Variables } & \multicolumn{2}{|c|}{ MDR-TB knowledge } & \multirow[b]{2}{*}{ COR $(95 \% \mathrm{Cl})$} & \multirow[b]{2}{*}{ AOR $(95 \% \mathrm{Cl})$} \\
\hline & Good & Poor & & \\
\hline \multicolumn{5}{|l|}{ Working site } \\
\hline Internal medicine & 37 & 40 & 1.00 & \\
\hline Surgery & 17 & 29 & 0.60 (0.28 to 1.26$)$ & \\
\hline Gynaecology and obstetrics & 17 & 26 & 0.67 (0.31 to 1.42$)$ & \\
\hline Paediatrics & 24 & 28 & 0.87 (0.43 to 1.77$)$ & \\
\hline OPD and others & 52 & 105 & 0.50 (0.29 to 0.88$)$ & \\
\hline \multicolumn{5}{|l|}{ Age (year) } \\
\hline$<25$ & 50 & 80 & 1.00 & \\
\hline $26-30$ & 80 & 109 & 1.17 (0.74 to 1.85$)$ & \\
\hline$>30$ & 19 & 39 & 0.77 (0.40 to 1.49$)$ & \\
\hline \multicolumn{5}{|l|}{ Sex } \\
\hline Male & 103 & 126 & 1.81 (1.17 to 2.80$)$ & \\
\hline Female & 46 & 102 & 1.00 & \\
\hline \multicolumn{5}{|l|}{ Marital status } \\
\hline Married & 57 & 98 & 0.82 (0.53 to 1.25$)$ & \\
\hline Not married & 92 & 130 & 1.00 & \\
\hline \multicolumn{5}{|l|}{ Profession } \\
\hline Doctor of Medicine & 42 & 17 & 1.00 & \\
\hline Nurse & 70 & 128 & 0.22 (0.11 to 0.41$)$ & \\
\hline Medical laboratory & 13 & 31 & 0.17 (0.07 to 0.40$)$ & \\
\hline Other health professionals & 24 & 52 & 0.18 (0.08 to 0.39$)$ & \\
\hline \multicolumn{5}{|l|}{ Educational level } \\
\hline Diploma & 16 & 59 & 1.00 & 1.00 \\
\hline $\mathrm{BSc}$ & 99 & 157 & 2.32 (1.26 to 4.26$)$ & 1.58 (0.81 to 3.05$)$ \\
\hline Postgraduate above & 34 & 12 & 10.44 (4.42 to 24.67$)$ & 5.78 (2.33 to 14.33$)$ \\
\hline \multicolumn{5}{|l|}{ Staff categories } \\
\hline Teaching staff & 35 & 21 & 3.00 (1.68 to 5.44$)$ & \\
\hline Hospital staff & 114 & 207 & 1.00 & \\
\hline \multicolumn{5}{|l|}{ Working experience (years) } \\
\hline$<3$ & 59 & 80 & 1.17 (0.73 to 1.88$)$ & \\
\hline 03June & 33 & 57 & 0.92 (0.53 to 1.58$)$ & \\
\hline$>6$ & 57 & 91 & 1.00 & \\
\hline \multicolumn{5}{|l|}{ Ever diagnosed for TB } \\
\hline Yes & 35 & 103 & 2.68 (1.69 to 4.25$)$ & 1.85 (1.12 to 3.03$)$ \\
\hline No & 114 & 125 & 1.00 & 1.00 \\
\hline \multicolumn{5}{|l|}{ Trained for infection prevention } \\
\hline Yes & 23 & 55 & 1.78 (1.04 to 3.05$)$ & 1.79 (1.00 to 3.17$)$ \\
\hline No & 126 & 172 & 1.00 & 1.00 \\
\hline
\end{tabular}

AOR, adjusted odds ratio; COR, crude odds ratio; MDR-TB, multidrug-resistant tuberculosis; OPD, outpatient departments; TB, tuberculosis.

such as Ethiopia. In our study, knowledge gaps were identified with regard to the definition of MDR-TB, the combination of nationally recommend drug and the duration of MDR-TB treatment. Similar findings were reported from previous studies. ${ }^{33} 34$ Health workers' knowledge about MDR-TB were associated with an increased level of education and taking of infection prevention training. Health workers who had a postgraduate degree had better 
Table 4 Factors associated with the self-reported practice of health workers regarding the prevention and control of MDR-TB at Gondar University Referral Hospital and Felege Hiwot Referral Hospital, Northwest Ethiopia

\begin{tabular}{|c|c|c|c|c|}
\hline \multirow[b]{2}{*}{ Variables } & \multicolumn{2}{|c|}{ Practice } & \multirow[b]{2}{*}{ COR $(95 \% \mathrm{Cl})$} & \multirow[b]{2}{*}{ AOR $(95 \% \mathrm{Cl})$} \\
\hline & Yes & No & & \\
\hline \multicolumn{5}{|l|}{ Working site } \\
\hline Internal medicine & 29 & 50 & 3.21 (1.71 to 6.04$)$ & 4.64 (1.99 to 10.81$)$ \\
\hline Surgery & 5 & 41 & 0.67 (0.24 to 1.88$)$ & 1.11 (0.33 to 3.74$)$ \\
\hline Gynaecology and obstetrics & 11 & 32 & 1.90 (0.84 to 4.28$)$ & 2.57 (0.95 to 6.99$)$ \\
\hline Paediatrics & 5 & 47 & 0.59 (0.21 to 1.63$)$ & 3.85 (1.11 to 13.34$)$ \\
\hline OPD and others & 24 & 133 & 1.00 & 1.00 \\
\hline \multicolumn{5}{|l|}{ Age (years) } \\
\hline$<25$ & 13 & 117 & 1.00 & 1.00 \\
\hline $26-30$ & 43 & 146 & 2.65 (1.36 to 5.16$)$ & 2.70 (1.27 to 5.76$)$ \\
\hline$>30$ & 18 & 40 & 4.05 (1.82 to 9.00$)$ & 4.42 (1.77 to 11.00$)$ \\
\hline \multicolumn{5}{|l|}{ Sex } \\
\hline Male & 34 & 195 & 1.00 & \\
\hline Female & 40 & 108 & 0.47 (0.28 to 0.78$)$ & \\
\hline \multicolumn{5}{|l|}{ Profession } \\
\hline Doctor of Medicine & 8 & 51 & 1.00 & 1.00 \\
\hline Nurse & 48 & 150 & 2.04 (0.90 to 4.60$)$ & 4.49 (1.03 to 19.47$)$ \\
\hline Medical laboratory & 7 & 37 & 1.20 (0.40 to 3.62$)$ & 5.21 (0.86 to 31.51) \\
\hline Other health professionals & 11 & 67 & 1.07 (0.44 to 2.88 ) & 2.20 (0.25 to 10.73$)$ \\
\hline Educational level & & & 1.00 & \\
\hline Diploma & 27 & 48 & 0.32 (0.18 to 0.58$)$ & \\
\hline $\mathrm{BSc}$ & 40 & 219 & $0.31(0.12$ to 0.81$)$ & \\
\hline Residence/masters and above & 7 & 39 & & \\
\hline \multicolumn{5}{|l|}{ Staff categories } \\
\hline Teaching staff & 13 & 43 & 1.28 (0.65 to 2.54$)$ & \\
\hline Hospital staff & 61 & 260 & 1.00 & \\
\hline \multicolumn{5}{|l|}{ Working experience (year) } \\
\hline$<3$ & 21 & 118 & 0.76 (0.41 to 1.41$)$ & \\
\hline 03June & 25 & 65 & 1.64 (0.88 to 3.05$)$ & \\
\hline$>6$ & 28 & 120 & 1.00 & \\
\hline Knowledge on MDR & 20 & 129 & $0.50(0.28$ to 0.88$)$ & \\
\hline Good & 54 & 174 & 1.00 & \\
\hline
\end{tabular}

COR, crude odds ratio; MDR multidrug-resistant; MDR-TB, multidrug-resistant tuberculosis; OPD, outpatient departments.

knowledge about MDR-TB than health workers who had a diploma. This disparity was even more pronounced in health professionals who had been trained for infection prevention in the last 12 months and who had been previously diagnosed for TB. This finding highlighted the importance of providing infection prevention training for health works to increase their knowledge about MDR-TB.

Our study also found that only one-fourth of health works had good self-reported practice towards the prevention and control of MDR-TB. This low MDR-TB prevention and control practice among health workers is particularly risky in high TB burden countries such as Ethiopia because outbreaks of MDR-TB may occur in the hospitals. A high rate of hospital transmission of MDR-TB has been reported in previous studies. ${ }^{35} 36$

With regard to the practice of referring to the treatment guidelines, it is only one-third $(32.6 \%)$ of participants had access to the MDR-TB guideline in the hospitals; and less than a third $(29.17 \%)$ of participants referred to these guidelines while treating the patients. Although this finding is consistent with a report by other studies that a high number of healthcare practitioners 
fail to comply with clinical practice guidelines, this is noteworthy finding. ${ }^{37}$ It is important that the regional health bureau and hospital administration address this issue by making the MDR-TB guidelines available to all health workers in the healthcare settings.

Although this study did not assess whether health workers used protective mask appropriately through observation, slightly more than a quarter $(27.3 \%)$ of participants reported that they always wore a protective mask when carrying out clinical procedures and attending patients. This is also a very low percentage, as all health workers should use protective masks when dealing with TB patients. This may indicate that health workers, their family members, their patients and all other persons they interact with will be at higher risk of infection with MDR-TB. ${ }^{39} 40$ This is especially important for medical doctors, health officers and nurses who have regular contact with the patients.

This study has several limitations. First, there is a possibility that health workers may not report their actual practices (due to social desirability bias) as the information was self-reported. Second, the findings of this study may not be generalisable to health workers in other hospitals of the country as the study was limited only to two referral hospitals in Amhara region. Third, there could be a possibility of selection bias as the number of health workers who had prior TB appeared to be exceptionally high $(36.6 \%)$, suggesting they may have been more interested to participate in the study. Fourth, given that the study was based on a cross-sectional study design, it is important to acknowledge that a temporal relationship between the explanatory and outcome variable could not be established.

\section{CONCLUSIONS}

This study has revealed poor knowledge and practice of health workers about MDR-TB prevention and control in Amhara region referral hospitals, Ethiopia. The study also found that higher educational level, provision of training and history of TB were significantly associated with good knowledge of health workers. This finding highlighted the importance of providing infection prevention training for health works to increase their knowledge about MDR-TB.

Acknowledgements The authors would like to acknowledge the University of Gondar for providing us financial support to undertake this study. We also thank all health workers and data collectors who participated in this study.

Contributors KAA designed the study, participated in the data collection, analysed the data, and drafted the manuscript. AAA participated in the data collection and revised the draft manuscript. SY, BDB, AA and DNK critically revised the manuscript for methodological and intellectual content. All authors read and approved the final version of the manuscript.

Funding This research was supported by funding from the University of Gondar. The funders had no role in study design, data collection and analysis, interpretation of data, the decision to publish, or preparation of the manuscript.

Competing interests None declared.

Patient consent for publication Not required.
Ethics approval This study was approved by the University of Gondar Ethics Review Board (reference number RPC/59/2014) on 26 March 2014 before initiation of the study. Permission was granted to access health workers from each hospital administrations.

Provenance and peer review Not commissioned; externally peer reviewed.

Data sharing statement The data that support the findings of this study are available from the corresponding author on reasonable request.

Open access This is an open access article distributed in accordance with the Creative Commons Attribution Non Commercial (CC BY-NC 4.0) license, which permits others to distribute, remix, adapt, build upon this work non-commercially, and license their derivative works on different terms, provided the original work is properly cited, appropriate credit is given, any changes made indicated, and the use is non-commercial. See: http://creativecommons.org/licenses/by-nc/4.0/.

\section{REFERENCES}

1. WHO. Definitions and reporting framework for tuberculosis -2013 revision (updated 2014). Geneva, Switzerland: World Health Organization, 2013.

2. WHO. Global Tuberculosis Control SURVEILLANCE, PLANNING, FINANCING. Switzerland: WHO Press, 2008.

3. Gandhi NR, Moll A, Sturm AW, et al. Extensively drug-resistant tuberculosis as a cause of death in patients co-infected with tuberculosis and HIV in a rural area of South Africa. Lancet 2006;368:1575-80

4. Shah NS, Wright A, Bai GH, et al. Worldwide emergence of extensively drug-resistant tuberculosis. Emerg Infect Dis 2007;13:380-7.

5. Migliori GB, Ortmann J, Girardi E, et al. SMIRA/TBNET Study Group. Extensively drug-resistant tuberculosis, Italy and Germany. Emerg Infect Dis 2007;13:780-2.

6. WHO. Global tuberculosis report 2015. 20th ed. Geneva, Switzerland: World Health Organization, 2015.

7. WHO. Global tuberculosis report 2017. Geneva: World Health Organization, 2017.

8. WHO. Companion handbook to the WHO guidelines for the programmatic management of drug-resistant tuberculosis. Geneva, Switzerland: World Health Organization, 2014.

9. Caminero JA. Multidrug-resistant tuberculosis: epidemiology, risk factors and case finding. Int J Tuberc Lung Dis 2010;14:382-90.

10. Dye C. Doomsday postponed? Preventing and reversing epidemics of drug-resistant tuberculosis. Nat Rev Microbiol 2009;7:81-7.

11. Faustini A, Hall AJ, Perucci CA. Risk factors for multidrug resistant tuberculosis in Europe: a systematic review. Thorax 2006;61:158-63.

12. Han LL, Sloutsky A, Canales R, et al. Acquisition of drug resistance in multidrug-resistant Mycobacterium tuberculosis during directly observed empiric retreatment with standardized regimens. Int $J$ Tuberc Lung Dis 2005;9:818-21.

13. Dheda K, Limberis JD, Pietersen E, et al. Outcomes, infectiousness, and transmission dynamics of patients with extensively drugresistant tuberculosis and home-discharged patients with programmatically incurable tuberculosis: a prospective cohort study. Lancet Respir Med 2017;5:269-81.

14. Ragonnet R, Trauer JM, Denholm JT, et al. High rates of multidrugresistant and rifampicin-resistant tuberculosis among re-treatment cases: where do they come from? BMC Infect Dis 2017;17:36.

15. Shah NS, Auld SC, Brust JC, et al. Transmission of Extensively Drug-Resistant Tuberculosis in South Africa. N Engl J Med 2017;376:243-53.

16. Van der Westhuizen $\mathrm{H}-\mathrm{M}$, Kotze $\mathrm{K}$, Narotam $\mathrm{H}$, et al. Knowledge, attitudes and practices regarding TB infection control among health science students in a TB-endemic setting. Int J Infect Control $2015 ; 11$.

17. von Delft A, Dramowski A, Sifumba Z, et al. Exposed, but not protected: more is needed to prevent drug-resistant tuberculosis in healthcare workers and students. Clin Infect Dis 2016;62 Suppl 3(suppl_3):S275-80.

18. Nathavitharana RR, Peters J, Lederer P, et al. Engaging health-care workers to reduce tuberculosis transmission. Lancet Infect Dis 2016;16:883-5.

19. Nathavitharana RR, Bond P, Dramowski A, et al. Agents of change: the role of healthcare workers in the prevention of nosocomial and occupational tuberculosis. Presse Med 2017;46:e53-62.

20. Demissie Gizaw G, Aderaw Alemu Z, Kibret KT. Assessment of knowledge and practice of health workers towards tuberculosis infection control and associated factors in public health facilities of 
Addis Ababa, Ethiopia: a cross-sectional study. Arch Public Health 2015;73:15.

21. WHO. Use of high burden country lists for tuberculosis by WHO in the post-2015 era. Geneva, Switzerland: WHO, 2015.

22. Economist. Unit TEl, ed. Tackling Tuberculosis in Ethiopia: a community-based approach, 2016.

23. $\mathrm{MOH}$. Annual Tuberculosis Bulletin. EFMo H, ed. An extract of five years' TB, TB/HIV and Leprosy Control Program Analysis (EFY 2000 -2005). Addis Ababa, Ethiopia: Health Promotion and Diseases Prevention Directorate, 2013.

24. Alene KA, Viney K, McBryde ES, et al. Treatment outcomes in patients with multidrug-resistant tuberculosis in north-west Ethiopia. Trop Med Int Health 2017;22:351-62.

25. Misganaw A, Haregu TN, Deribe K, et al. National mortality burden due to communicable, non-communicable, and other diseases in Ethiopia, 1990-2015: findings from the Global Burden of Disease Study 2015. Popul Health Metr 2017;15:29.

26. Biruck Kebede BA, Kassa A, Walelgne W, et al. Guidelines on Programmatic Management of Drug Resistant Tuberculosis in Ethiopia. Addis Ababa, Ethiopia: Health FDROEMO, 2013.

27. WHO. Companion handbook to the WHO guidelines for the programmatic management of drug-resistant tuberculosis. Geneva, Switzerland: WHO, 2014.

28. Hashim DS, Al Kubaisy W, Al Dulayme A. Knowledge, attitudes and practices survey among health care workers and tuberculosis patients in Iraq. East Mediterr Health J 2003:9:718-31.

29. Hoa NP, Chuc NTK, Thorson A. Knowledge, attitudes, and practices about tuberculosis and choice of communication channels in a rural community in Vietnam. Health Policy 2009;90:8-12.

30. Kiefer EM, Shao T, Carrasquillo O, et al. Knowledge and attitudes of tuberculosis management in San Juan de Lurigancho district of Lima, Peru. J Infect Dev Ctries 2009;3:783-8.
31. Kanjee Z, Catterick K, Moll AP, et al. Tuberculosis infection control in rural South Africa: survey of knowledge, attitude and practice in hospital staff. $J$ Hosp Infect 2011;79:333-8.

32. van der Werf MJ, Langendam MW, Huitric E, et al. Knowledge of tuberculosis-treatment prescription of health workers: a systematic review. Eur Respir J 2012;39:erj01256-2011.

33. Malangu N, Adebanjo OD. Knowledge and practices about multidrug-resistant tuberculosis amongst healthcare workers in Maseru. Afr J Prim Health Care Fam Med 2015;7:1-5.

34. Tefera G, Seid Y. Actual practice of healthcare providers towards prevention and control of Multidrug-resistant tuberculosis (MDR-TB) at Borumeda Hospital, Ethiopia. African Journal of Pharmacy and Pharmacology 2017;11:152-60.

35. Crudu V, Merker M, Lange C, et al. Nosocomial transmission of multidrug-resistant tuberculosis. Int J Tuberc Lung Dis 2015;19:1520-3.

36. Bantubani N, Kabera G, Connolly C, et al. High rates of potentially infectious tuberculosis and multidrug-resistant tuberculosis (MDRTB) among hospital inpatients in KwaZulu Natal, South Africa indicate risk of nosocomial transmission. PLoS One 2014;9:e90868.

37. Cabana MD, Rand CS, Powe NR, et al. Why don't physicians follow clinical practice guidelines? A framework for improvement. JAMA 1999;282:458-1465.

38. Holtz TH, Lancaster J, Laserson KF, et al. Risk factors associated with default from multidrug-resistant tuberculosis treatment, South Africa, 1999-2001. Int J Tuberc Lung Dis 2006;10:649-55.

39. Schaaf HS, Moll AP, Dheda K. Multidrug- and extensively drugresistant tuberculosis in Africa and South America: epidemiology, diagnosis and management in adults and children. Clin Chest Med 2009;30:667-83.

40. Zhao M, Li X, Xu P, et al. Transmission of MDR and XDR tuberculosis in Shanghai, China. PLoS One 2009;4:4370:e4370. 